Fixed Point Theory, 19(2018), No. 1, 379-382

DOI $10.24193 /$ fpt-ro.2018.1.29

http://www.math.ubbcluj.ro/ ${ }_{\text {nodeacj/sfptcj.html }}$

\title{
HYERS-ULAM STABILITY OF THE LAPLACE OPERATOR
}

\author{
DORIAN POPA AND IOAN RAŞA \\ Technical University of Cluj-Napoca, Department of Mathematics, \\ 28 Memorandumului Street, 400114, Cluj-Napoca, Romania \\ E-mail: Popa.Dorian@math.utcluj.ro \\ Ioan.Rasa@math.utcluj.ro
}

Abstract. We investigate the Hyers-Ulam stability of the Laplace operator $\Delta$ and of a multiple of it, acting on suitable domains. Moreover, we obtain an explicit representation of the Hyers-Ulam constant.

Key Words and Phrases: Hyers-Ulam stability, Laplace operator, Digamma function.

2010 Mathematics Subject Classification: 39B82, 35J15, 47S07.

\section{REFERENCES}

[1] M. Abramowitz, I.A. Stegun, Handbook of Mathematical Functions and Formulas, Graphs and Mathematical Tables, New-York, Dover, 1972.

[2] F. Altomare and M. Campiti, Korovkin-type Approximation Theory and its Applications, W. De Gruyter, Berlin - New York, 1994.

[3] F. Altomare, M. Cappelletti Montano, V. Leonessa, I. Raşa, Markov Operators, Positive Semigroups and Approximation Processes, W. De Gruyter Studies in Mathematics, Vol. 61, 2014.

[4] Sz. András, A.R. Mészáros, Ulam-Hyers stability of elliptic partial differential equations in Sobolev spaces, Appl. Math. Comput., 229(2014), 131-138.

[5] E. Gselmann, Stability properties in some classes of second order partial differential equations, Results Math., 65(2014), 95-103.

[6] O. Hatori, K. Kobayasi, T. Miura, H. Takagi, S.E. Takahasi, On the best constant of Hyers-Ulam stability, J. Nonlinear Convex Anal., 5(2004), 387-393.

[7] B. Hegyi, S.-M. Jung, On the stability of Laplace's equation, Appl. Math. Lett., 26(2013), 549-552.

[8] D.H. Hyers, G. Isac, Th. M. Rassias, Stability of Functional Equations in Several Variables, Birkhäuser, Basel, 1998.

[9] R. Precup, Linear and semilinear partial differential equations, W. De Gruyter, 2013.

[10] I. Raşa, Positive operators, Feller semigroups and diffusion equations associated with Altomare projections, Conf. Sem. Mat. Univ. Bari, 284(2002), 26 pp.

[11] H. Takagi, T. Miura, S.-E. Takahasi, Essential norms and stability constants of weighted composition operators on $C(X)$, Bull. Korean Math. Soc., 40(2003), 583-591.

Received: May 8, 2015; Accepted: July 2, 2015. 